\title{
High Temperatures and Kidney Disease Morbidity: A Systematic Review and Meta-analysis
}

\author{
Woo-Seok Lee' ${ }^{1}$, Woo-Sung Kim ${ }^{1}$, Youn-Hee Lim ${ }^{2,3}$, Yun-Chul Hong ${ }^{1,2,3}$ \\ ${ }^{1}$ Department of Preventive Medicine, Seoul National University College of Medicine, Seoul, Korea; ${ }^{2}$ Institute of Environmental Medicine, Seoul \\ National University Medical Research Center, Seoul, Korea; ${ }^{3}$ Environmental Health Center, Seoul National University College of Medicine, Seoul, \\ Korea
}

Objectives: In recent years, serious concerns have been raised regarding the impacts of rising temperatures on health. The present study was conducted to investigate the relationship between elevated temperatures and kidney disease through a systematic review and meta-analysis.

Methods: In October 2017, 2 researchers independently searched related studies in PubMed and Embase. A meta-analysis was conducted using a random-effects model, including only studies that presented odds ratios, relative risks, or percentage changes, along with $95 \%$ confidence intervals (Cls). The characteristics of each study were summarized, and the Egger test and funnel plots were used to evaluate publication bias.

Results: Eleven studies that met the criteria were included in the final analysis. The pooled results suggest an increase of $30 \%(95 \% \mathrm{Cl}$, 20 to 40) in kidney disease morbidity with high temperatures. In a disease-specific subgroup analysis, statistically significant results were observed for both renal colic or kidney stones and other renal diseases. In a study design-specific subgroup analysis, statistically significant results were observed in both time-series analyses and studies with other designs. In a temperature measure-specific subgroup analysis, significant results were likewise found for both studies using mean temperature measurements and studies measuring heat waves or heat stress.

Conclusions: Our results indicate that morbidity due to kidney disease increases at high temperatures. We also found significant results in subgroup analyses. However, further time-series analyses are needed to obtain more generalizable evidence.

Key words: High temperature, Kidney diseases, Systematic review, Meta-analysis

\section{INTRODUCTION}

Recent increases in global temperature have raised concerns regarding the impacts of high temperatures on health. How-

Received: July 2, 2018 Accepted: November 1, 2018

Corresponding author: Yun-Chul Hong, MD, PhD

Department of Preventive Medicine, Seoul National University College of Medicine, 103 Daehak-ro, Jongno-gu, Seoul 03080, Korea

E-mail: ychong1@snu.ac.kr

This is an Open Access article distributed under the terms of the Creative Commons Attribution Non-Commercial License (http://creativecommons.org/licenses/bync/4.0/) which permits unrestricted non-commercial use, distribution, and reproduction in any medium, provided the original work is properly cited. ever, the impacts of extreme weather vary across regions [1,2]. Studies of the health effects of high temperatures have been conducted, but most were studies on mortality. Meanwhile, few studies have investigated the impacts of high temperatures on morbidity [3-7].

Studying the health effects of rising temperatures can promote public health in multiple ways [3]. First, an understanding of how temperature affects mortality and morbidity in various populations can help predict how temperature changes will affect human health [3]. Based on these results, public health interventions can be targeted towards vulnerable subgroups $[3,8]$. Second, such analyses can provide new insights 
into ways of reducing the socioeconomic burden associated with major chronic diseases, such as cardiovascular, respiratory, and renal diseases [3,9].

An insufficient number of studies have investigated the relationships of changes in temperature with the development of kidney disease [10]. In some studies, however, it has been documented that extremely hot weather can cause susceptible subjects to experience heat-related conditions, such as hyperthermia and heat stress or strain; meanwhile, adjusting the body temperature and circulation to cope with elevated temperatures can put stress on the kidneys and impair the function of the renal system [11-17]. According to a study by Kovats and Hajat [13], a remarkable spike in emergency admissions for kidney disease occurred due to a rise in temperature. In particular, this tendency has been found in vulnerable groups in various studies [14-17]. For example, people who are at risk of developing kidney dysfunction, such as the elderly, are at high risks of hyperthermia, electrolyte imbalance, dehydration, acute renal failure, heat stroke, and heat strain in extremely hot weather [10,13-17].

Although previous studies have shown associations between high temperatures and kidney disease, no systematic review and meta-analysis of the relationship between high temperatures and kidney disease has been conducted. Therefore, this study aimed to evaluate the associations between high temperatures and morbidity due to kidney disease through a systematic review and meta-analysis.

\section{METHODS}

\section{Study Selection}

Two independent researchers (WSL and WSK; both medical doctors) searched for related studies in PubMed and Embase in October 2017, using the title index (TI). The search keywords were related to high temperatures ("hot" [TI] or "heat" [TI] or "temperature" [TI] or "warm" [TI]) and kidney disease ("nephro" [TI] or "kidney" [TI] or "renal" [TI] or "genitourinary" [TI] or "calculus" [TI] or "hospital admission" [TI] or "hospitalization" [TI] or "emergency room visit" [TI] or "emergency department visit" [TI]). We used the TI because too many words such as "hot topic" or "hot issue" or "hot pepper" appeared in full-text searchers. The search language was limited to English and Korean.

The titles and abstracts of relevant studies were first reviewed, and then the whole text was reviewed. Two researchers independently checked each article, and if their opinions differed, a third researcher (YHL; PhD in health statistics) mediated the final decision. The studies to be analyzed were limited to those on human populations and included all ages. The research designs included in the analysis were case-crossover studies, cohort studies, and time-series analyses. We excluded reviews, letters, case reports, gray literature, pre-clinical studies, and studies without an abstract or full text [18]. We required the effect estimates of the studies to be presented as odds ratios (ORs), relative risks (RRs), or percentage changes, along with 95\% confidence intervals (Cls).

\section{Statistical Analysis}

The results of the studies included in the analysis were summarized and tabulated. In most studies, the efficacy estimates were expressed as ORs or RRs with $95 \% \mathrm{Cls}$, but percent changes were reported in some studies [3]. The results presented as percent changes were converted to ORs. The summarized statistics are expressed as RRs with $95 \% \mathrm{Cls}$ [3]. Some studies had thresholds and showed effects at temperatures above the threshold. Temperatures presented in Fahrenheit $\left({ }^{\circ} \mathrm{F}\right)$ were converted to Celsius $\left({ }^{\circ} \mathrm{C}\right)$. The results extracted from the studies were transformed to a logarithmic scale for the meta-analysis. Stata version 14.2 (StataCorp., College Station, TX, USA) was used for the meta-analysis of all results.

If considerable heterogeneity was found between studies, we calculated the combined effect estimates by a random-effects model [3]. The $l^{2}$ statistic was used to measure heterogeneity, which was classified as low when $l^{2}$ was less than $25 \%$, moderate between $25 \%$ and $75 \%$, and high at values of $75 \%$ or more [18]. In order to evaluate the possible demographic variables that could affect kidney disease, we performed subgroup analyses for disease (renal colic or kidney stones vs. other kidney diseases), study design (time series vs. other study designs), and the temperature measure (mean temperature vs. heat wave or heat strain). For other kidney diseases and other study designs, the number of studies was too small for a more specific analysis, so they were bundled into the category of 'other.'

The Egger test was used to evaluate publication bias, and the degree of symmetry in the funnel plot was observed $[19,20]$. The $p$-value for statistical significance was derived from the Egger test.

\section{Quality Assessment}

The Newcastle-Ottawa Scale (NOS) was used to assess the quality of the studies. Because of the variable characteristics of 
exposure to rising temperatures, it is difficult to study this issue in a randomized manner, so all studies included in the analysis were observational. Assessing the quality of observational studies is essential for properly understanding their findings and the significance thereof. The NOS is a quality-assessment measure developed by researchers at the University of Newcastle, Australia, and the University of Ottawa, Canada. This scale can be used both for randomized studies and for observational studies, and it is widely used for the interpretation of results in meta-analyses. In the following 3 broad categories, each item is assessed, and a star is awarded according to a predetermined standard: selection of subjects, the comparability of the study groups, and the ascertainment of exposure or outcome for each study design $[18,21]$. We defined good-quality studies as those with 3 or 4 stars in the selection domain, 1 or 2 stars in the comparability domain, and 2 or 3 stars in the exposure/outcome domain [21]. Fair-quality studies were defined as those with 2 stars in the selection domain, 1 or 2 stars in the comparability domain, and 2 or 3 stars in the exposure/outcome domain. Poor-quality studies were those with 0 or 1 star in the selection domain, 0 stars in the comparability domain, or 0 or 1 star in the exposure/outcome domain [21].

\section{RESULTS}

A total of 844 papers were found in the initial search: 376 through PubMed and 468 through Embase. After removing 474 duplicates, the title and abstract of 370 papers were reviewed. After reviewing the title and abstract, 299 articles were excluded, and 71 articles underwent full-text review. After excluding 60 articles according to the selection criteria, 11 studies were selected for the meta-analysis. Figure S1 displays a schematic diagram of the search process.

Table 1 shows the information extracted from the studies included in the analysis. Of the studies included in the analysis, 4 were studies on renal colic or kidney stone, 3 presented results for the incidence or hospital admissions of kidney disease, 2 provided results for acute kidney injury admissions, and 2 presented effect estimates of incidence or hospital admissions for acute renal failure. A time-series design was applied in most of the studies, using either a distributed lag nonlinear model (DLNM) or a generalized additive model.

Confounding factors, such as atmospheric pressure, humidity, wind speed, air pollution, influenza or pneumonia, day of the week, the holiday effect, long-term trends, daily fluctuations in outdoor activities, and season [10,12,22-25] were considered. In most studies, temperature was defined as the daily average temperature and daily maximum temperature, but some studies used the daily minimum temperature or apparent temperature [3]. A lag effect was considered in almost all studies, ranging from 0 to 21 days.

Several approaches were used to assess the associations between temperature and kidney disease morbidity. Six studies had thresholds above a particular temperature. In these studies, various techniques were used to identify the threshold values. In the absence of thresholds, some studies investigated the effects of high temperatures above a certain percentile. In studies with thresholds, temperatures ranging from $25.4^{\circ} \mathrm{C}$ to $35.0^{\circ} \mathrm{C}$ were the thresholds for high-temperature effects.

Most studies predicted that there would be a change in the effect of high temperatures based on a certain threshold, instead of a perfectly linear relationship. Only 1 study assumed that the effects of temperature would be linear [25]. To investigate delayed effects and non-linear associations between high temperatures and kidney disease, some studies used a DLNM [24]. The advantage of this model is that it can calculate the cumulative effect of temperature on several days after adjusting for the collinearity of temperature on adjacent dates and estimating the non-linear exposure-response association $[24,31]$. Table 2 summarizes the results of each of the studies included in the meta-analysis.

Figure 1 shows the results of a meta-analysis of all studies on high temperatures and kidney disease morbidity. Tasian et al. [22] presented results for 5 metropolitan cities (Atlanta, GA, Chicago, IL, Dallas, TX, Los Angeles, CA, and Philadelphia, PA) in the USA. Tawatsupa et al. [27] presented separate results by sex (male vs. female) in Thailand. Tasian et al. [22] and Tawatsupa et al. [27] did not present aggregated results; instead, each result was presented separately. The estimates of pooled effects for all studies using a random-effects model showed that high temperatures were associated with a $30 \%$ increase in kidney disease morbidity $(95 \% \mathrm{Cl}, 20$ to 40$)$.

Subgroup analyses were performed for renal colic or kidney stones in comparison to other kidney diseases. Because the number of studies with diseases other than renal colic or kidney stones was too small, the broad category of other kidney diseases was used. Figure 2 shows the results of the diseasespecific subgroup meta-analysis. For renal colic or kidney stones, high temperatures increased the risk of disease by $32 \%$ 


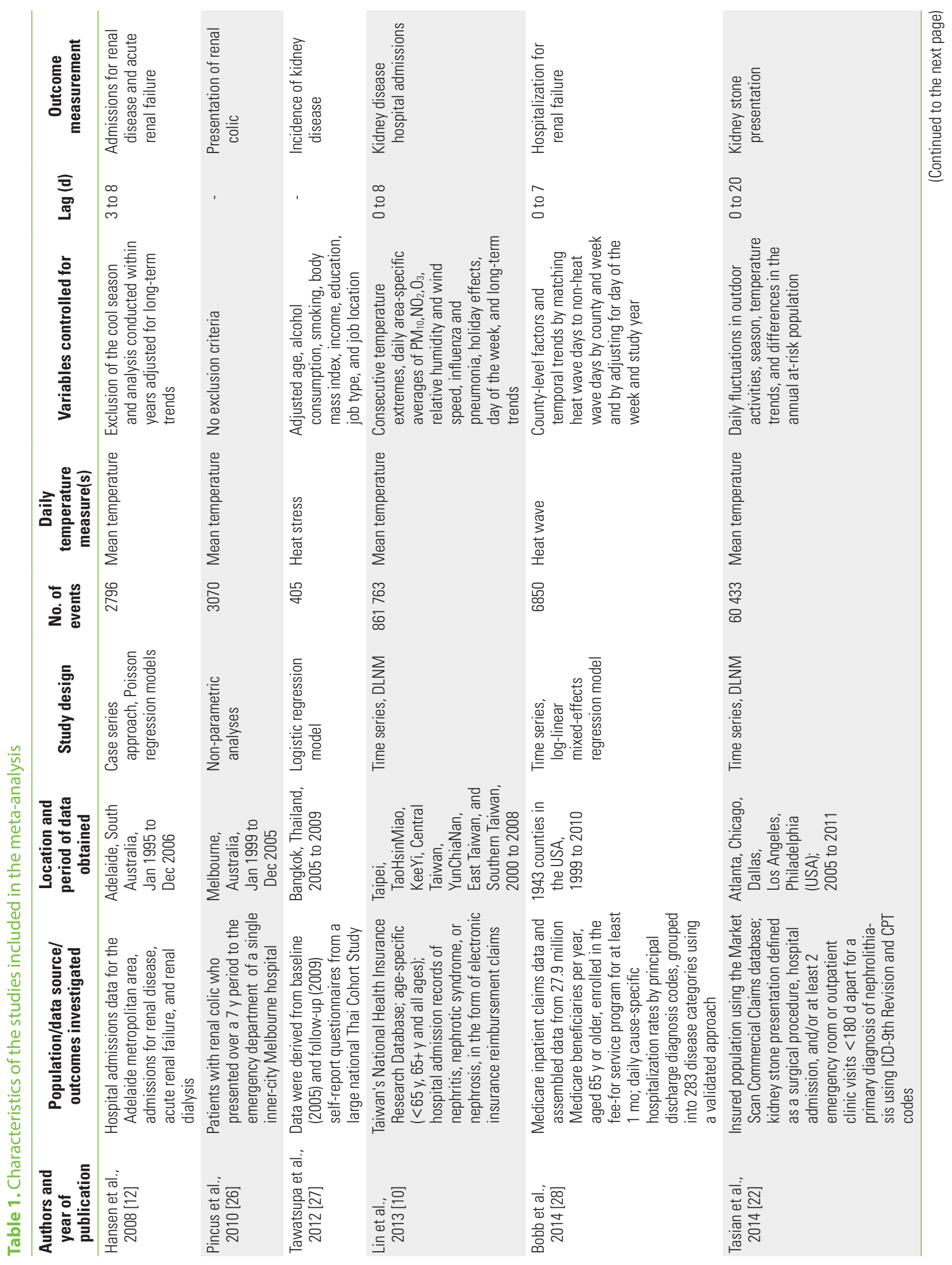




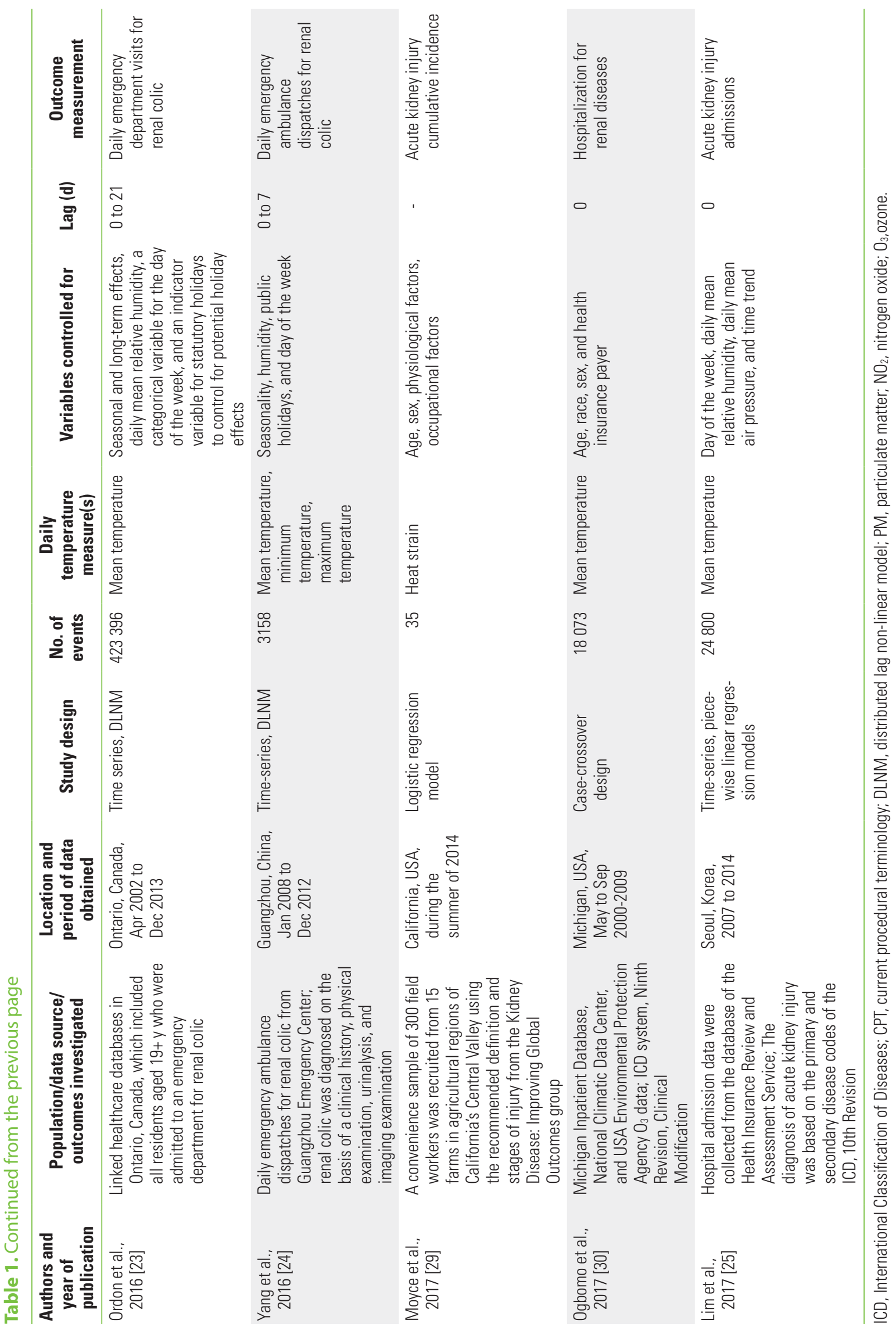


Table 2. Results extracted from the studies included in the meta-analysis

\begin{tabular}{|c|c|c|c|c|c|}
\hline $\begin{array}{l}\text { Author and } \\
\text { year of } \\
\text { publication }\end{array}$ & $\begin{array}{l}\text { Temperature variable } \\
\text { and range }\left({ }^{\circ} \mathrm{C}\right)\end{array}$ & $\begin{array}{l}\text { RR/rate ratio } \\
(95 \% \mathrm{CI})\end{array}$ & $\begin{array}{c}\text { Temperature } \\
\text { threshold }\end{array}$ & Units of study results & Outcome and subgroup \\
\hline $\begin{array}{l}\text { Hansen et al., } \\
2008 \text { [12] }\end{array}$ & $\begin{array}{l}\text { Mean temperature } \\
\text { (4.4 to 41.9) }\end{array}$ & $\begin{array}{l}1.10(1.00,1.22) \\
1.12(0.98,1.26) \\
1.10(1.03,1.15) \\
1.13(1.02,1.26) \\
1.16(0.99,1.33) \\
1.10(1.02,1.18) \\
1.09(0.98,1.20) \\
1.05(0.92,1.20) \\
1.08(0.99,1.19) \\
1.20(1.04,1.38) \\
1.05(0.82,1.34) \\
1.22(1.02,1.45)\end{array}$ & $\begin{array}{l}35 \\
35 \\
35 \\
35 \\
35 \\
35 \\
35 \\
35 \\
35 \\
35 \\
35 \\
35\end{array}$ & $\begin{array}{l}\text { Hospital admissions for } \\
\text { renal disease during heat } \\
\text { waves ( } 3 \text { or more } \\
\text { consecutive days when } \\
\text { daily maximum } \\
\text { temperatures reached } \\
\text { or exceeded } 35^{\circ} \mathrm{C} \text { in the } \\
\text { warm season) compared } \\
\text { with non-heat wave } \\
\text { periods }\end{array}$ & $\begin{array}{l}\text { Hospital admissions for renal disease (Adelaide) } \\
\text { All } \\
\text { Male } \\
\text { Female } \\
15-64 \text { y } \\
\text { Male } \\
\text { Female } \\
\geq 65 \text { y } \\
\text { Male } \\
\text { Female } \\
\geq 85 \text { y } \\
\text { Male } \\
\text { Female }\end{array}$ \\
\hline $\begin{array}{l}\text { Pincus et al., } \\
2010[26]\end{array}$ & $\begin{array}{l}\text { Mean temperature } \\
\text { (14.2 to } 30.1)\end{array}$ & $1.29(1.15,1.43)$ & - & $\begin{array}{l}\text { The summer/winter ratio of } \\
\text { renal colic incidence }\end{array}$ & Presentations of renal colic, all, Melbourne \\
\hline $\begin{array}{l}\text { Tawatsupa } \\
\text { et al., } 2012 \\
\text { [27] }\end{array}$ & Heat stress & $\begin{array}{l}1.48(1.01,2.16) \\
0.87(0.59,1.28)\end{array}$ & - & $\begin{array}{l}\text { Incidence of kidney disease } \\
\text { during heat stress } \\
\text { compared with non-heat } \\
\text { stress }\end{array}$ & $\begin{array}{l}\text { Incidence of kidney disease, Bangkok } \\
\text { Male } \\
\text { Female }\end{array}$ \\
\hline $\begin{array}{l}\text { Lin et al., } \\
2013[10]\end{array}$ & $\begin{array}{l}\text { Mean temperature } \\
\text { (14.2 to } 30.1)\end{array}$ & $1.45(1.27,1.64)$ & 30 & $\begin{array}{l}\text { Kidney disease hospital } \\
\text { admissions at } 30^{\circ} \mathrm{C} \\
\text { compared with at } 25^{\circ} \mathrm{C}\end{array}$ & $\begin{array}{l}\text { Kidney disease hospital admissions, all, } 7 \text { study } \\
\text { areas in Taiwan }\end{array}$ \\
\hline $\begin{array}{l}\text { Bobb et al., } \\
2014 \text { [28] }\end{array}$ & Heat wave & $1.14(1.06,1.23)$ & - & $\begin{array}{l}\text { Hospitalization for renal } \\
\text { failure during heat wave } \\
\text { periods compared with } \\
\text { non-heat wave periods }\end{array}$ & Hospitalization for renal failure, all, USA \\
\hline $\begin{array}{l}\text { Ordon et al., } \\
2016 \text { [23] }\end{array}$ & $\begin{array}{l}\text { Mean temperature } \\
(-7.0 \text { to } 25.4)\end{array}$ & $\begin{array}{l}1.48(1.33,1.64) \\
1.32(1.08,1.60) \\
1.52(1.24,1.86) \\
1.83(1.48,2.27) \\
1.44(1.06,1.96) \\
1.14(0.80,1.63)\end{array}$ & $\begin{array}{l}25.4 \\
25.4 \\
25.4 \\
25.4 \\
25.4 \\
\\
25.4 \\
25.4\end{array}$ & $\begin{array}{l}\text { The effect of increased } \\
\text { ambient temperatures on } \\
\text { daily emergency } \\
\text { department visits for } \\
\text { renal colic (extreme heat } \\
\text { effect: 99th vs. 10th } \\
\text { percentile) }\end{array}$ & $\begin{array}{l}\text { Daily emergency department visits for renal colic (Ontario) } \\
\text { All } \\
\text { Age (y) } \\
19-39 \\
40-49 \\
50-59 \\
60-69 \\
\geq 70 \\
\text { Sex } \\
\text { Male } \\
\text { Female }\end{array}$ \\
\hline $\begin{array}{l}\text { Yang et al., } \\
2016[24]\end{array}$ & $\begin{array}{l}\text { Mean temperature (4.8 } \\
\text { to } 33.9) \text {, minimum } \\
\text { temperature (1.8 to } \\
\text { 29.7), maximum } \\
\text { temperature ( } 7.0 \text { to } \\
\text { 40.0) }\end{array}$ & $1.92(1.21,3.05)$ & 30.7 & $\begin{array}{l}\text { RR comparing the 90th } \\
\text { percentile of temperature } \\
\text { distribution with the } \\
\text { reference }\left(21.0^{\circ} \mathrm{C}\right)\end{array}$ & $\begin{array}{l}\text { Daily emergency ambulance dispatches for renal } \\
\text { colic, all, Guangzhou }\end{array}$ \\
\hline
\end{tabular}


Table 2. Continued from the previous page

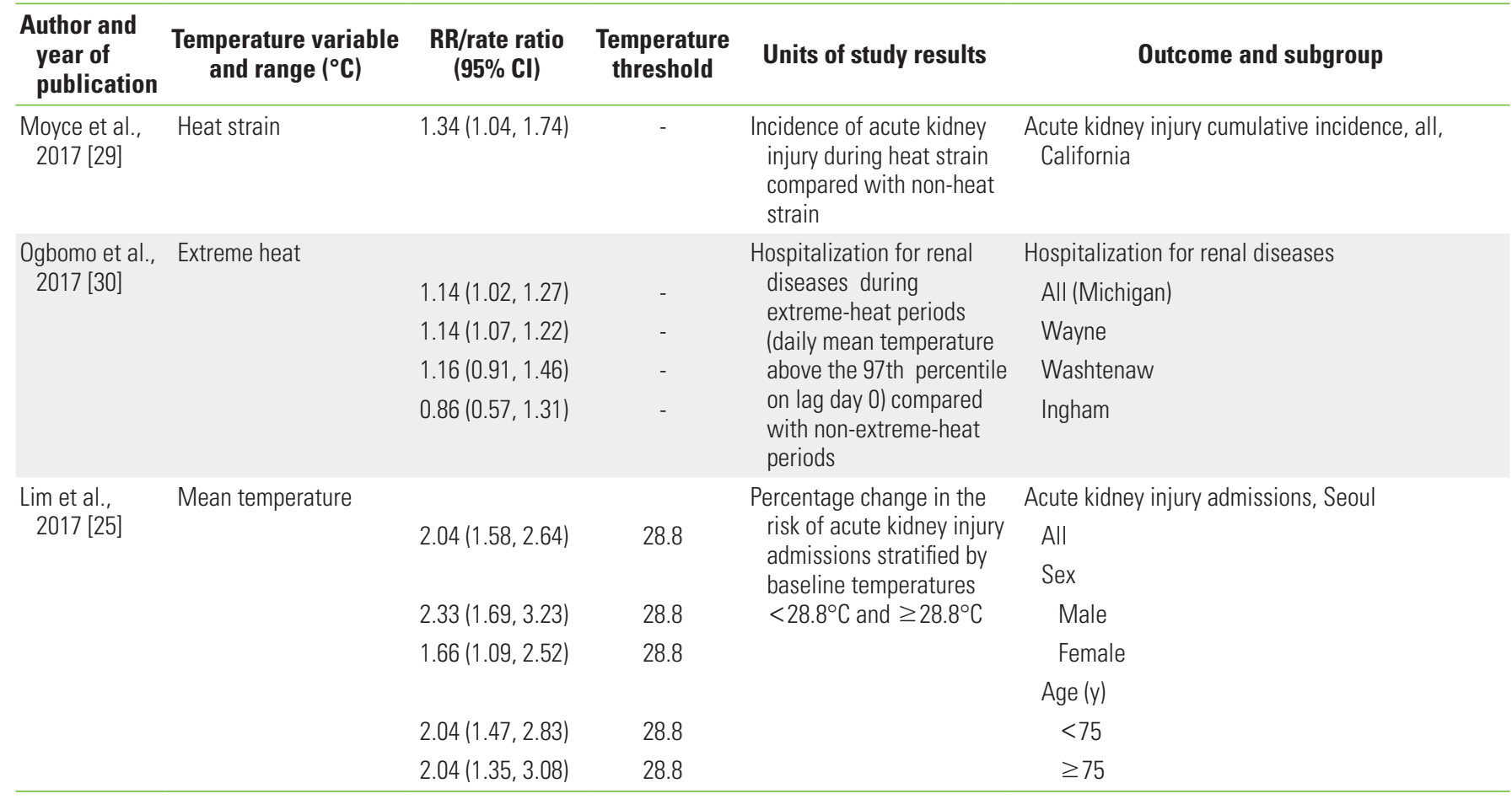

$\mathrm{RR}$, relative risks; $\mathrm{Cl}$, confidence interval.

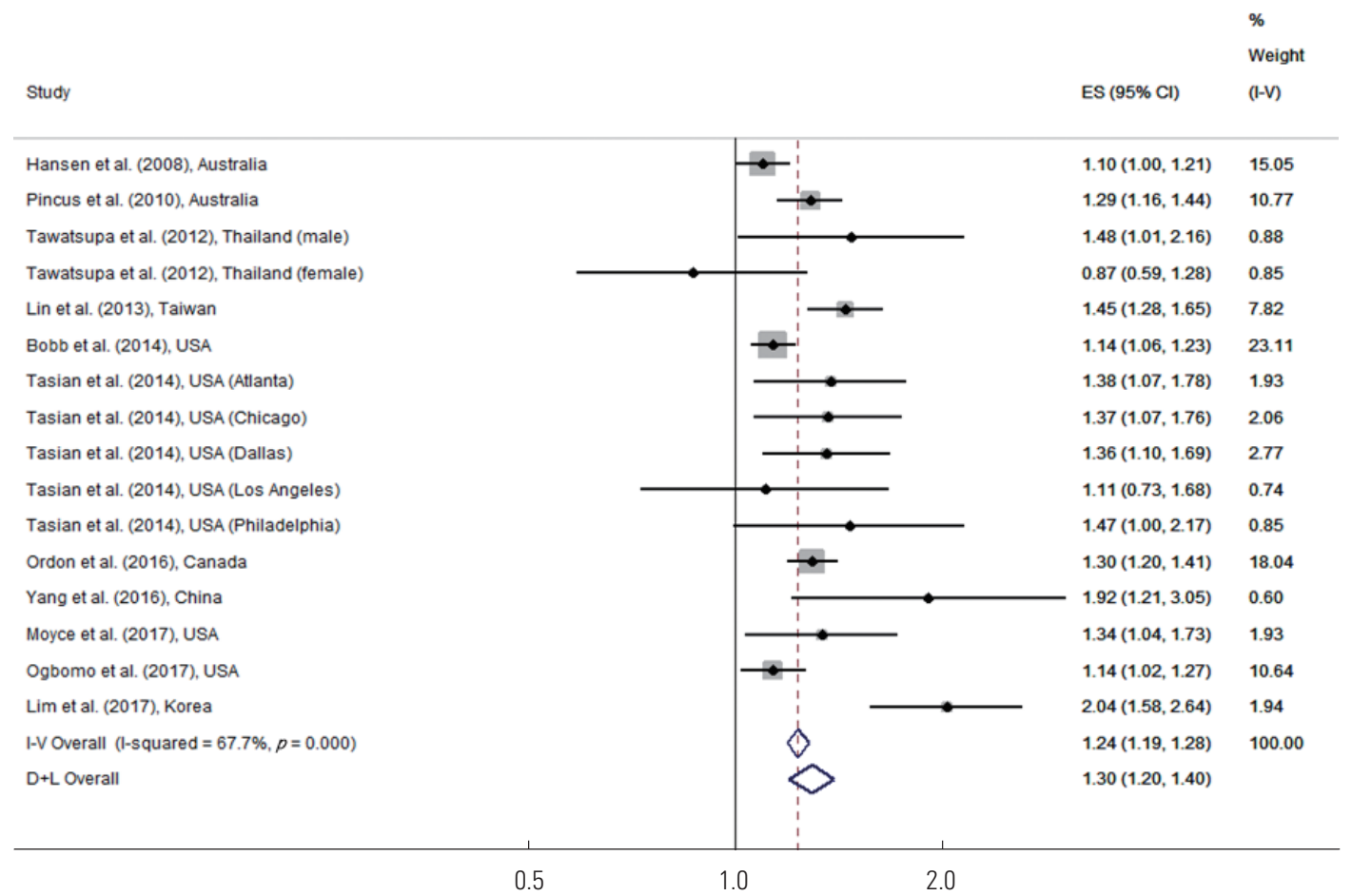

Figure 1. Meta-analysis (overall study, ordered by the year of publication) of heat effects on kidney disease morbidity. ES, effect size (per allele odds ratio); I-V overall, inverse-variance fixed effects estimate; D+L overall, DerSimonian and Laird random-effects estimate. 


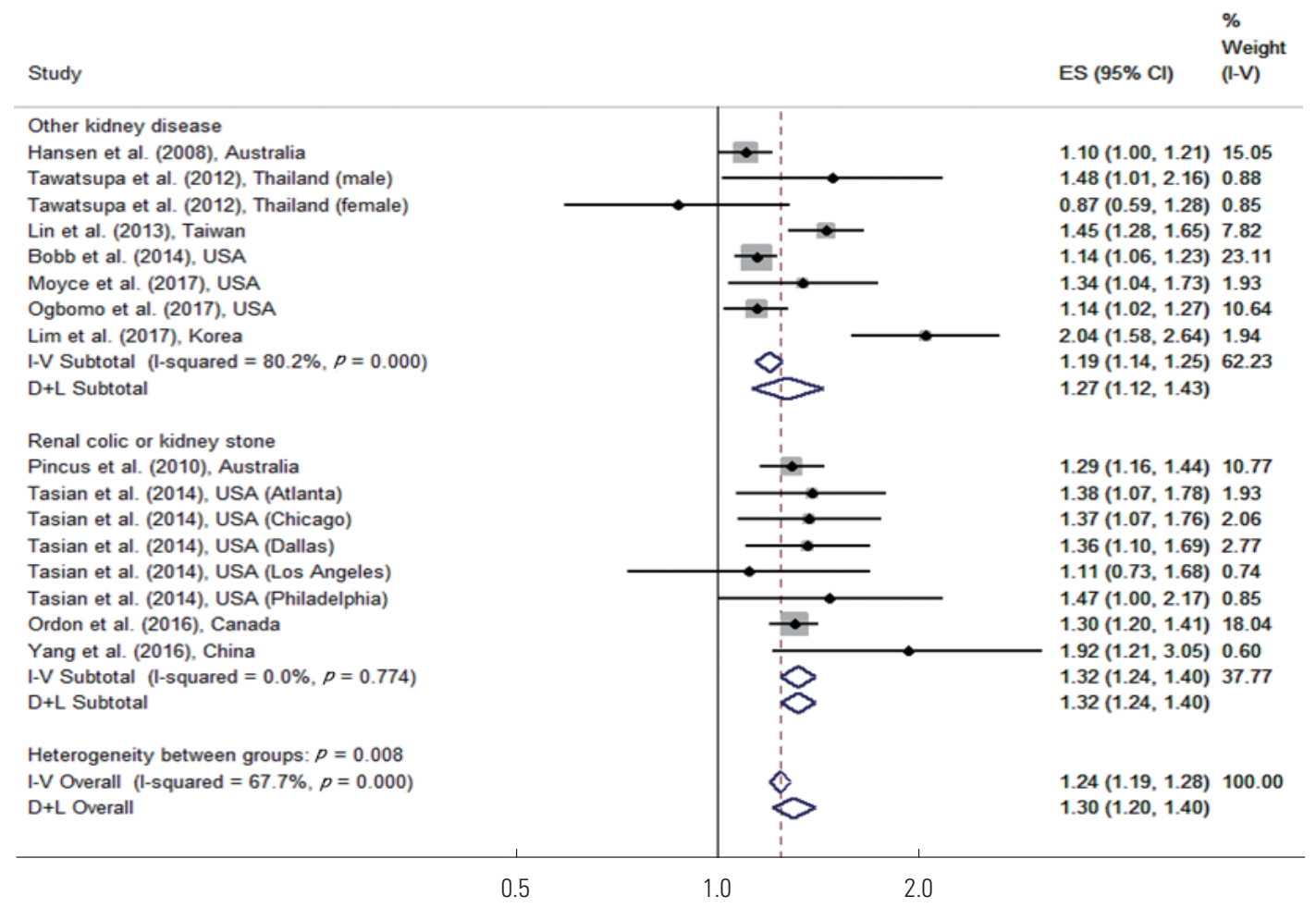

Figure 2. Meta-analysis (disease-specific and overall, ordered by the year of publication) of heat effects on morbidity related to renal colic or kidney stone, other kidney disease. ES, effect size (per allele odds ratio); I-V overall, inverse-variance fixed effects estimate; D+L overall, DerSimonian and Laird random-effects estimate.

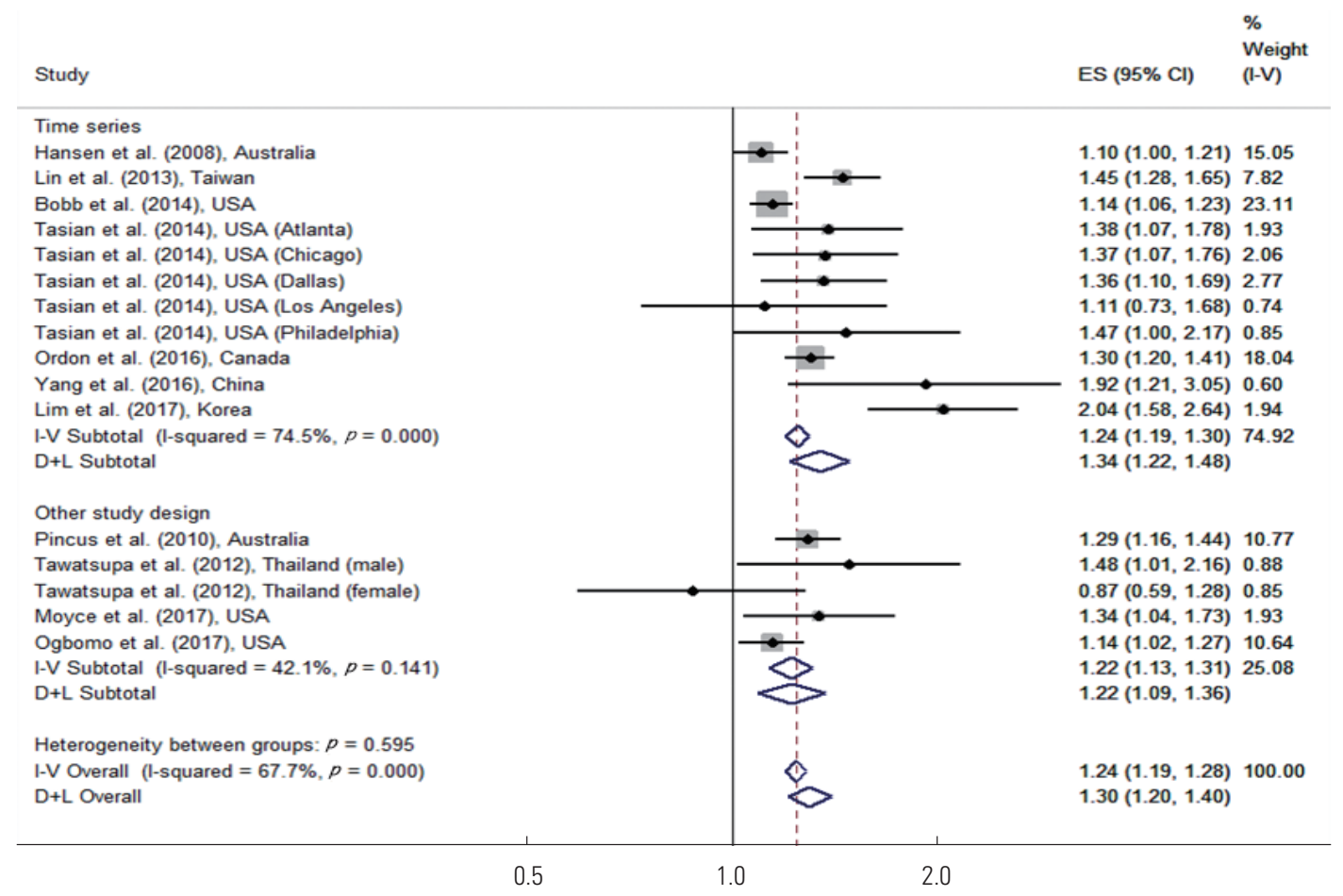

Figure 3. Meta-analysis (study design-specific and overall, ordered by the year of publication) of heat effects on morbidity related to time series, other study design. ES, effect size (per allele odds ratio); I-V overall, inverse-variance fixed effects estimate; $D+L$ overall, DerSimonian and Laird random-effects estimate. 


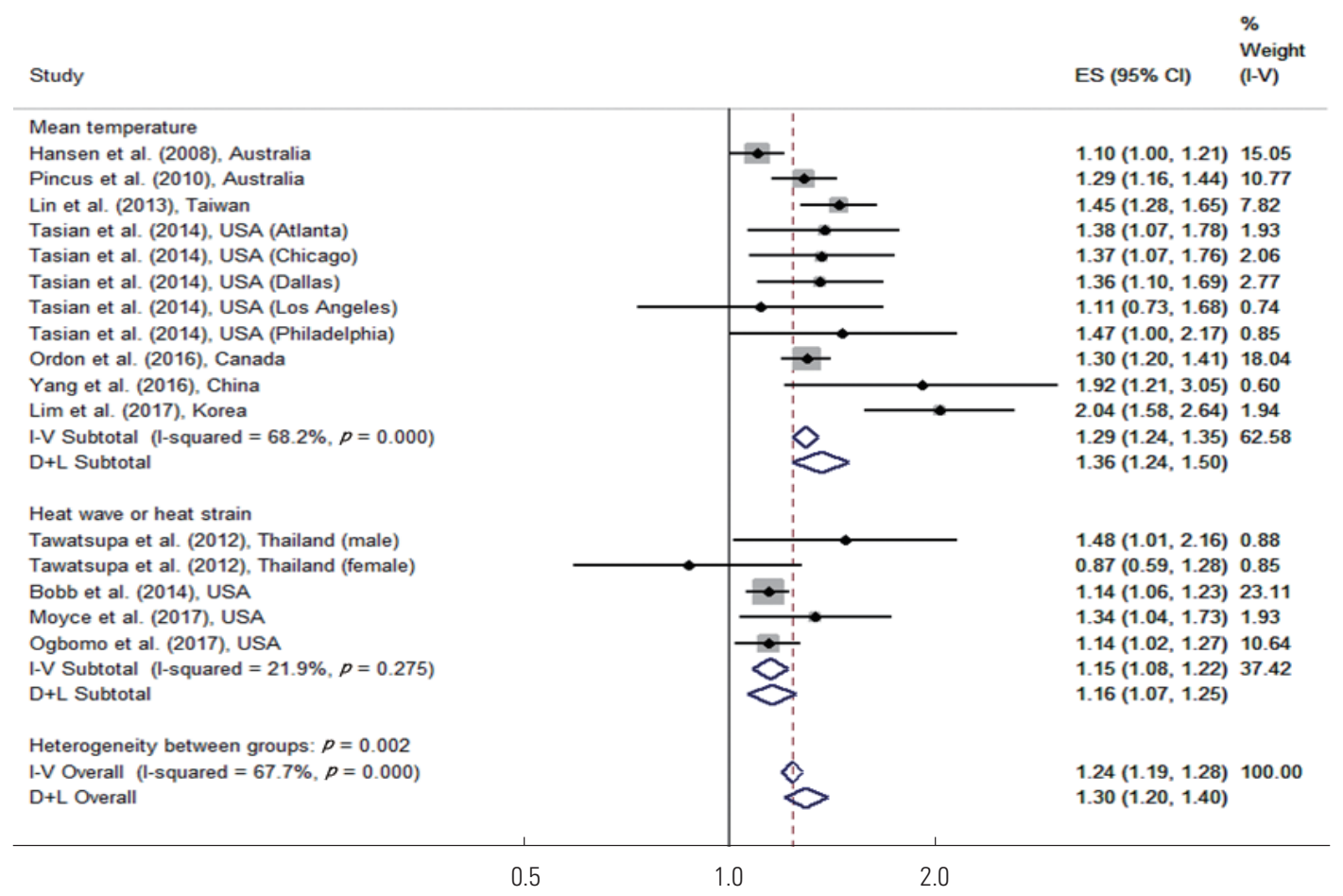

Figure 4. Meta-analysis (temperature measure-specific and overall, ordered by the year of publication) of heat effects on morbidity related to mean temperature, heat wave or heat strain. ES, effect size (per allele odds ratio); I-V overall, inverse-variance fixed effects estimate; D+L overall, DerSimonian and Laird random-effects estimate.

(95\% Cl, 24 to 40). For other kidney diseases, high temperatures increased the risk of disease by $27 \%(95 \% \mathrm{Cl}, 12$ to 43$)$, and both of these results were statistically significant.

A subgroup analysis was also performed for time-series studies in comparison to studies with other designs. Pincus et al. [26], Tawatsupa et al. [27], Moyce et al. [29], and Ogbomo et al. [30] utilized other study designs. Figure 3 shows the results of the study design-specific subgroup meta-analysis. In the time-series studies, high temperatures increased the risk of disease by $34 \%$ (95\% Cl, 22 to 48). In studies with another design, high temperatures increased the risk of disease by $22 \%(95 \% \mathrm{Cl}, 9$ to 36), and both of these results were statistically significant.

An additional subgroup analysis was performed based on whether studies defined high temperatures in terms of the mean temperature or in terms of heat wave or heat strain. Tawatsupa et al. [27], Bobb et al. [28], and Moyce et al. [29] used heat wave or heat strain. Figure 4 shows the results of the temperature measure-specific subgroup meta-analysis. In studies that used the mean temperature, high temperatures increased the risk of disease by $36 \%(95 \% \mathrm{Cl}, 24$ to 50$)$, which was statistically significant. In studies that used heat stress or heat strain, high temperature increased the risk of disease by
$16 \%$ (95\% Cl, 7 to 25$)$, which was also statistically significant.

For all study and subgroup analyses, the $P^{2}$ values ranged from $21.9 \%$ to $80.2 \%$ and the heterogeneity across the studies was moderate. Since the $l^{2}$ value of all studies was more than $50 \%$, the use of a variable-effects model was considered appropriate.

In order to examine the tendency toward publication bias in a schematic manner, we created a funnel plot as shown in Figure S2. We concluded that the possibility of publication bias was low because the funnel plot was relatively symmetrical and the result of the Egger test was not statistically significant $(p=0.083)$.

We conducted a quality assessment of the 11 studies included in the meta-analysis, as shown in Table S1. The majority of the studies included in the meta-analysis were of good quality. However, the studies of Tawatsupa et al. [27] and Moyce et al. [29] were assessed as fair-quality.

\section{DISCUSSION}

This meta-analysis evaluated the effects of high temperatures on kidney disease morbidity, and confirmed that elevat- 
ed temperatures were associated with kidney disease. Both disease- and study design-based subgroup analyses showed consistent results. However, in the disease-specific subgroup analysis, the effect estimate for renal colic or kidney stones was larger than for other kidney diseases. In the study designspecific subgroup analysis, the effect estimate of the time-series analyses was larger than that of studies with other designs. In the subgroup analysis according to the temperature measurement method, both groups showed significant results. However, the effect size was larger in the studies where the threshold temperature was set by measuring the mean temperature.

The effects of high temperatures are generally acute and are known to occur in a short period of time [3,32]. Our results for other kidney diseases support these observations. However, renal colic and kidney stones showed longer lag effects. Although it is difficult to reach definitive conclusions about the lag effects of heat because of the small number of studies, most kidney diseases tend to occur within a short period of time, whereas kidney stones may take some time to develop.

In other meta-analyses, the mortality rate due to high temperatures varied across studies; however, it was found that mortality increased by $1 \%-5 \%$ when the temperature rose by $1{ }^{\circ} \mathrm{C}$ and that heat-related deaths were mostly caused by cardiovascular and respiratory diseases, especially in the elderly [33]. In addition, the mortality rates were particularly high among those confined to bed and among those with mental illnesses [34]. In other meta-analyses on morbidity, blood pressure became significantly elevated as temperature dropped [35]. As temperature increases, so does the risk of various diseases, such as diarrhea [36], dengue fever [37], and cardiovascular and respiratory diseases [3].

In the literature search, we found that studies on kidney disease due to elevated temperatures included acute renal failure, acute kidney injury, kidney stones, renal colic, abnormal kidney function, and kidney tumors. Many studies of acute kidney injury and acute renal failure analyzed workers in hightemperature environments or people who engaged in outdoor activities. Studies of renal dysfunction and kidney tumors, in contrast, were generally based on experimental studies or hypotheses. In studies of abnormal kidney function, the index for evaluating renal function was not unified, and a different index was presented in each study. Therefore, we did not include abnormal kidney function or kidney tumors in this meta-analysis.

The heterogeneity observed in the sensitivity analyses and the variability among study results may be related to various factors. The fact that most of the studies were performed in temperate regions supports pooling the studies. However, differences in the locations where the studies were conducted likely contributed to the observed heterogeneity. It is also possible that factors such as other research periods, different characteristics of the population groups, and socioeconomic conditions contributed to the heterogeneity [3], as well as other factors such as the use of air conditioners [38]. It is also possible that differences in research design, different modeling methods, and the use of different confounding variables led to heterogeneity.

We indirectly considered the effects of adaptation to high temperatures on kidney disease in this study by only including studies that showed RRs at or above the threshold temperature compared to below the threshold temperature, which was determined based on an assessment of the temperature at which changes in disease morbidity were expected in the study area.

The effect of diurnal temperature range on kidney disease may be another issue to consider. To the best of our knowledge, studies on the diurnal temperature range and kidney disease have not yet been conducted, but studies have investigated the relationships of the diurnal temperature range with mortality, cardiovascular disease, and respiratory diseases $[39,40]$. In some of those studies, the results were significant, suggesting that further studies on diurnal variation and kidney disease will be necessary $[39,40]$.

The present study has the following strengths. First, this is the first meta-analysis of associations between high temperature and morbidity due to kidney disease, to the best of our knowledge. Second, the Egger test and a funnel plot analysis showed that the possibility of publication bias was low, and the quality of the studies included in the meta-analysis was quite good, as assessed using the NOS.

This study also has several limitations. First, the number of studies included in the meta-analysis was relatively small, and the research design focused on time-series analyses. The studies were conducted in limited areas, and therefore do not reflect the impact of all climatic conditions [3]. For this reason, caution is needed when generalizing the results through a meta-analysis. However, we observed consistent results in the studies included in the meta-analysis, and the relatively high 
quality of these studies further confirms the reliability of our findings. Second, we used the TI and only included published studies. Therefore, there is a possibility that publication bias may have been caused by excluding unpublished studies or studies not found through the TI [18]. However, the Egger test showed that our results were not significantly affected by publication bias. Third, studies using different criteria for high temperatures were included in this meta-analysis; for examples, some studies used the criterion of a specific temperature percentile, some used threshold values determined through a dedicated analysis, and others focused on heat wave events. This means that the meta-analysis was conducted without standardizing the criteria for defining high temperatures. Therefore, careful attention should be paid to the linear analysis of the results, even though a random-effects model was applied. Finally, there could have been significant differences among the studies included in this meta-analysis according to the study method, sample size, sex and age of the study population, and discrepancies in the kidney function and kidney disease indices used in each study.

\section{CONCLUSION}

We found that morbidity due to kidney diseases increases at high temperatures. This finding suggests that public awareness and surveillance of kidney disease, particularly kidney stones, is necessary when temperatures become elevated.

\section{SUPPLEMENTARY MATERIALS}

Supplementary materials are available at https://www.jpmph. org/.

\section{CONFLICT OF INTEREST}

The authors have no conflicts of interest associated with the material presented in this paper.

\section{ACKNOWLEDGEMENTS}

This study was supported by the Korea Centers for Disease Control and Prevention (KCDC) (\#20180202D8A-00 [Year 20172018]) of the Republic of Korea.

\section{ORCID}

Woo-Seok Lee http://orcid.org/0000-0002-0862-2862

Woo-Sung Kim http://orcid.org/0000-0003-3404-5576

Youn-Hee Lim http://orcid.org/0000-0002-1290-5814

Yun-Chul Hong http://orcid.org/0000-0001-9010-7271

\section{REFERENCES}

1. Blashki G, Armstrong G, Berry HL, Weaver HJ, Hanna EG, Bi P, et al. Preparing health services for climate change in Australia. Asia Pac J Public Health 2011;23(2 Suppl):133S-143S.

2. Barriopedro D, Fischer EM, Luterbacher J, Trigo RM, GarcíaHerrera R. The hot summer of 2010: redrawing the temperature record map of Europe. Science 2011;332(6026):220-224.

3. Turner LR, Barnett AG, Connell D, Tong S. Ambient temperature and cardiorespiratory morbidity: a systematic review and meta-analysis. Epidemiology 2012;23(4):594-606.

4. Ostro B, Rauch S, Green S. Quantifying the health impacts of future changes in temperature in California. Environ Res 2011; 111(8):1258-1264.

5. Knowlton K, Rotkin-Ellman M, King G, Margolis HG, Smith D, Solomon G, et al. The 2006 California heat wave: impacts on hospitalizations and emergency department visits. Environ Health Perspect 2009;117(1):61-67.

6. Hajat S, O'Connor M, Kosatsky T. Health effects of hot weather: from awareness of risk factors to effective health protection. Lancet 2010;375(9717):856-863.

7. Intergovernmental Panel on Climate Change (IPCC). Climate change 2007: synthesis report [cited 2019 Jan 18]. Available from: https://www.globalchange.gov/browse/reports/ipccclimate-change-2007-synthesis-report.

8. Bassil KL, Cole DC. Effectiveness of public health interventions in reducing morbidity and mortality during heat episodes: a structured review. Int J Environ Res Public Health 2010;7(3): 991-1001.

9. Trogdon JG, Finkelstein EA, Nwaise IA, Tangka FK, Orenstein D. The economic burden of chronic cardiovascular disease for major insurers. Health Promot Pract 2007;8(3):234-242.

10. Lin YK, Wang YC, Ho TJ, Lu CA. Temperature effects on hospital admissions for kidney morbidity in Taiwan. Sci Total Environ 2013;443:812-820.

11. Semenza JC, McCullough JE, Flanders WD, McGeehin MA, Lumpkin JR. Excess hospital admissions during the July 1995 heat wave in Chicago. Am J Prev Med 1999;16(4):269-277. 
12. Hansen AL, Bi P, Ryan P, Nitschke M, Pisaniello D, Tucker G. The effect of heat waves on hospital admissions for renal disease in a temperate city of Australia. Int J Epidemiol 2008;37(6): 1359-1365.

13. Kovats RS, Hajat S. Heat stress and public health: a critical review. Annu Rev Public Health 2008;29:41-55.

14. Flynn A, McGreevy C, Mulkerrin EC. Why do older patients die in a heatwave? QJM 2005;98(3):227-229.

15. Semenza JC. Acute renal failure during heat waves. Am J Prev Med 1999;17(1):97.

16. Tan W, Herzlich BC, Funaro R, Koutelos K, Pagala M, Amaladevi $B$, et al. Rhabdomyolysis and myoglobinuric acute renal failure associated with classic heat stroke. South Med J 1995;88(10): 1065-1068.

17. Varghese GM, John G, Thomas K, Abraham OC, Mathai D. Predictors of multi-organ dysfunction in heatstroke. Emerg Med J 2005;22(3):185-187.

18. Jung SJ, Woo HT, Cho S, Park K, Jeong S, Lee YJ, et al. Association between body size, weight change and depression: systematic review and meta-analysis. Br J Psychiatry 2017;211(1):14-21.

19. Egger M, Davey Smith G, Schneider M, Minder C. Bias in metaanalysis detected by a simple, graphical test. BMJ 1997;315 (7109):629-634.

20. Lim H, Kwon HJ, Lim JA, Choi JH, Ha M, Hwang SS, et al. Shortterm effect of fine particulate matter on children's hospital admissions and emergency department visits for asthma: a systematic review and meta-analysis. J Prev Med Public Health 2016;49(4):205-219.

21. Wells GA, Shea B, O'Connell D, Peterson J, Welch V, Losos M, et al. The Newcastle-Ottawa Scale (NOS) for assessing the quality of nonrandomised studies in meta-analyses [cited $2018 \mathrm{Jul}$ 1]. Available from: http://www.ohri.ca/programs/clinical_epidemiology/oxford.asp.

22. Tasian GE, Pulido JE, Gasparrini A, Saigal CS, Horton BP, Landis $J R$, et al. Daily mean temperature and clinical kidney stone presentation in five U.S. metropolitan areas: a time-series analysis. Environ Health Perspect 2014;122(10):1081-1087.

23. Ordon M, Welk B, Li Q, Wang J, Lavigne E, Yagouti A, et al. Ambient temperature and the risk of renal colic: a populationbased study of the impact of demographics and comorbidity. J Endourol 2016;30(10):1138-1143.

24. Yang C, Chen X, Chen R, Cai J, Meng X, Wan Y, et al. Daily ambient temperature and renal colic incidence in Guangzhou, China: a time-series analysis. Int J Biometeorol 2016;60(8): 1135-1142.
25. Lim YH, So R, Lee C, Hong YC, Park M, Kim L, et al. Ambient temperature and hospital admissions for acute kidney injury: a time-series analysis. Sci Total Environ 2018;616-617:1134-1138.

26. Pincus S, Macbean C, Taylor D. The effects of temperature, age and sex on presentations of renal colic in Melbourne, Australia. Eur J Emerg Med 2010;17(6):328-331.

27. Tawatsupa B, Lim LL, Kjellstrom T, Seubsman SA, Sleigh A; Thai Cohort Study Team. Association between occupational heat stress and kidney disease among 37,816 workers in the Thai Cohort Study (TCS). J Epidemiol 2012;22(3):251-260.

28. Bobb JF, Obermeyer Z, Wang Y, Dominici F. Cause-specific risk of hospital admission related to extreme heat in older adults. JAMA 2014;312(24):2659-2667.

29. Moyce S, Mitchell D, Armitage T, Tancredi D, Joseph J, Schenker M. Heat strain, volume depletion and kidney function in California agricultural workers. Occup Environ Med 2017;74(6):402-409.

30. Ogbomo AS, Gronlund CJ, O'Neill MS, Konen T, Cameron L, Wahl R. Vulnerability to extreme-heat-associated hospitalization in three counties in Michigan, USA, 2000-2009. Int J Biometeorol 2017;61(5):833-843.

31. Gasparrini A. Distributed lag linear and non-linear models in R: the package dlnm. J Stat Softw 2011;43(8):1-20.

32. Anderson BG, Bell ML. Weather-related mortality: how heat, cold, and heat waves affect mortality in the United States. Epidemiology 2009;20(2):205-213.

33. Bunker A, Wildenhain J, Vandenbergh A, Henschke N, Rocklöv J, Hajat $S$, et al. Effects of air temperature on climate-sensitive mortality and morbidity outcomes in the elderly; a systematic review and meta-analysis of epidemiological evidence. EBioMedicine 2016;6:258-268.

34. Bouchama A, Dehbi M, Mohamed G, Matthies F, Shoukri M, Menne B. Prognostic factors in heat wave related deaths: a meta-analysis. Arch Intern Med 2007;167(20):2170-2176.

35. Wang Q, Li C, Guo Y, Barnett AG, Tong S, Phung D, et al. Environmental ambient temperature and blood pressure in adults: a systematic review and meta-analysis. Sci Total Environ 2017; 575:276-286.

36. Carlton EJ, Woster AP, DeWitt P, Goldstein RS, Levy K. A systematic review and meta-analysis of ambient temperature and diarrhoeal diseases. Int J Epidemiol 2016;45(1):117-130.

37. Fan J, Wei W, Bai Z, Fan C, Li S, Liu Q, et al. A systematic review and meta-analysis of dengue risk with temperature change. Int J Environ Res Public Health 2014;12(1):1-15.

38. Ostro B, Rauch S, Green R, Malig B, Basu R. The effects of temperature and use of air conditioning on hospitalizations. Am J 
Epidemiol 2010;172(9):1053-1061.

39. Lim YH, Reid CE, Mann JK, Jerrett M, Kim H. Diurnal temperature range and short-term mortality in large US communities. Int J Biometeorol 2015;59(9):1311-1319.
40. Lim YH, Hong YC, Kim H. Effects of diurnal temperature range on cardiovascular and respiratory hospital admissions in Korea. Sci Total Environ 2012;417-418:55-60. 